\title{
Monoamine Oxidase A Gene Polymorphisms and Bipolar Disorder in Iranian Population
}

\author{
Mohammad Reza Eslami Amirabadi ${ }^{1}$; Sepideh Rajezi Esfahani ${ }^{1}$; Rozita Davari-Ashtiani ${ }^{2}$; Mo- \\ jgan Khademi ${ }^{2}$; Babak Emamalizadeh ${ }^{3}$; Abolfazl Movafagh ${ }^{3}$; Said Sadr ${ }^{2}$; Fariba Arabgol ${ }^{2}$; \\ Hossein Darvish ${ }^{3, *} ;$ Katayoon Razjoyan $^{2, *}$ \\ ${ }_{2}^{1}$ Behavioral Sciences Research Center, Shahid Beheshti University of Medical Sciences, Tehran, IR Iran \\ 2 pepartment of Psychiatry, Imam Hossein Hospital, Shahid Beheshti University of Medical Sciences, Tehran, IR Iran \\ ${ }^{3}$ Department of Medical Genetics, Shahid Beheshti University of Medical Sciences, Tehran, Iran \\ *Corresponding Authors: Katayoon Razjoyan, Department of Psychiatry, Imam Hossein Hospital, Shahid Beheshti University of Medical Sciences, Tehran, IR Iran. Tel/fax: +98- \\ 2123872572, E-mail:k_razjouyan@sbmu.ac.ir; Hossein Darvish, Department of Medical Genetics, Shahid Beheshti University of Medical Sciences, Tehran, Iran. Tel/fax: +98-2123872572, \\ E-mail: darvish_mg@yahoo.com.
}

Received: August 27, 2014; Revised: September 23, 2014; Accepted: November 9, 2014

\begin{abstract}
Background:Bipolar disorder (BPD) is a common and severe mood disorder. Although genetic factors have important rolesin the etiology of bipolar disorder, no specific gene has been identified in relation to this disorder. Monoamine oxidase gene is suggested to be associated with bipolar disorder in many studies.

Objectives: This study aimed to investigatethe role of MAOA gene polymorphisms in the etiology of bipolar disorder in Iranian population. Patients and Methods: This study is a case-control study, with convenient sampling. Three common polymorphisms, a CA microsatellite, a VNTR, and a RFLP were typed in 156 bipolar patients and 173 healthy controls. Patients were chosen from Imam Hossein General Hospital, Psychiatry Ward (Tehran/Iran). Controlsamples for this study consisted of 173 healthy individuals recruitedby convenient sampling. Allelic distributions of these polymorphisms were analyzed in bipolar and control groups to investigate any association with MAOA gene.

Results: Significant associations were observed regarding $M A O A-C A(P=0.016)$ and $M A O A-V N T R(P=0.004)$ polymorphisms in the bipolar females. There was no association between MAOA-RFLP and bipolar disorder.

Conclusions: The obtained results confirm some previous studies regardinga gender specific association of MAOA gene with the bipolar disorder.
\end{abstract}

Keywords:Bipolar Disorder; Genetic Association Studies; Genetics; Monoamine Oxidase; Iran

\section{Background}

Bipolar disorder(BPD) is a common and severe mood disorder characterized by manic and depressive episodes. Approximately $1.0 \%$ of the general population (ranging from $0.1 \%$ in Nigeria to $3.3 \%$ in the United States) meet lifetime criteria for BP type I (BP-I) (1). The familial aggregation of bipolar disorder is well established $(2,3)$. Both adoption (4) and twin (5) studies show that a substantial proportion of the variance in the etiology of bipolar disorder may be attributed to genetic factors. Although much data support a genetic component in the etiology of bipolar affective disorder, the mode(s) of inheritance are unclear and the specific genes associated with predisposition to this condition have not been well-characterized (6).

One candidate gene on the $\mathrm{X}$ chromosome that is of particular interest for bipolar disorder is the gene for monoamine oxidase A. Monoamine oxidase is an enzyme expressed in the outer mitochondrial membrane; it catalyzes the degradation of biological amines (7). The first association of the MAOA gene with psychiatric disease was reported in a study of a large family in Holland (8). In many studies, MAOA gene had been identified as a significant issue related to psychological disease such as BPD (9), depression (10-13) and antidepressant response (12), sleep quality (11), alcoholism combined with BPD (14), impulsive behaviors and alcohol dependence (15), alcoholism (13), and paranoid schizophrenia $(16,17)$.

The association of MAOA polymorphisms with BPD has been contradictory in different populations. For example, while studies conducted in Germany (18), the U.S.A. (19), Canada $(20,21)$, and China $(22,23)$ have shown no associations in their overall samples, positive correlations have been reported from studies conducted in Japan (24), Canada (25), China $(26,27)$, South Africa (28), and the UK (29). Furthermore, studies done in France, Switzerland (30), and the UK (31) have reported positive correlations in female subjects only. Recently, in a meta-analysis, the association between MAOA and mood disorders was confirmed. Their results demonstrated significant association 
between UVNTR and MDD in the Asian group or male Asian group, CA polymorphism, and BPD in all Caucasians for the overall alleles. They concluded the MAOA gene can be associated with mood disorders by sex and ethnicity (10).

Studies of the association between bipolar disorder and $M A O A$ have mainly focused on 3 markers in this gene: 1) a dinucleotide repeat polymorphism referred to as $M A O A$ CA (32), 2) a dinucleotide repeat directly adjacent to the imperfectly duplicated 23-base-pair variable number of tandem repeats (VNTR) motif (33), and 3) a restriction fragment length polymorphism (RFLP) resulting from single-base-pair substitution in the third base of a triplet codon (34).

As differences across studies may be attributable to either undetected population stratification or real genetic differences between study populations, conducting similar studies with different populations are crucial. Thus, in the present study, we examined all 3 polymorphisms in the Iranian population, and observed some significant associations similar to some other populations and different from others.

\section{Objectives}

This study aimed to investigate the role of MAOA gene polymorphisms in the etiology of bipolar disorder in Iranian population.

\section{Patients and Methods}

This study is a case-control research. To determine the sample size, the following equation (35) was used.

$$
n=\frac{T^{2} \mathrm{pq}}{d^{2}}
$$

Where $\mathrm{T}=1.96, \mathrm{p}=0.5, \mathrm{q}=0.5$, and $\mathrm{d}=0.11$. The minimum sample size needed to obtain statistically valid results was 79 , and we added 80 more to the sample to obtain higher validity.

The participants of the present study were recruited by convenient sampling method, from the department of psychiatry at Imam Hossein Hospital in Tehran, Iran from January 2013 to February 2014. Bipolar disorder type I was diagnosed based on the DSM-IV-TR criteria using a psychiatric interview Structured Clinical Interview for DSM-IV (SCID-I) (36) by 2 psychiatrists. Subjects with a history of, or a current neurological disease, or mental retardation were excluded. Samples for this study consisted of 156 unrelated bipolar patients and 173 healthy controls. The control samples had no evidence of psychiatric disorders in their family histories confirmed by a psychiatrist. The patients were in the range of $18-60$ years old, and normal samples were matched to patient samples in terms of age, sex, and ethnicity.

This study was approved by Ethics Committee of Behavioral Sciences Research Center of ShahidBeheshti Univer- sity of Medical Sciences. All participants provided written consent.

Genomic DNA was extracted from $2 \mathrm{~mL}$ of peripheral blood using salting-out method: $50 \mathrm{ng}$ of each of the primers, $0.2 \mathrm{mMdNTP}, 1.5 \mathrm{mM}$ magnesium chloride, and I unit of Taq polymerase in total reaction volume of $20 \mu \mathrm{L}$. The PCR primer used for amplifying 3 polymorphisms is presented below.

\section{1) $M A O A-C A$ \\ F: 5`AGAGACTAGACAAGTTGCAC 3’ \\ R: $5^{\prime}$ CACTATCTTGTTAGCTCACT $3^{\prime}$}

30 cycles, $94^{\circ} \mathrm{C}$ denaturation, $56.5^{\circ} \mathrm{C}$ annealing, and $72^{\circ} \mathrm{C}$ extension

2) $M A O A-V N T R$

F: 5' GGTAGACTCCTTTAAGAAAA 3'

R: $5^{\prime}$ CAATAAATGTCCTACACCTT 3 -

30 cycles, $94^{\circ} \mathrm{C}$ denaturation, $55.5^{\circ} \mathrm{C}$ annealing, and $72^{\circ} \mathrm{C}$ extension

3) MAOA-RFLP

F: 5' GACCTTGACTGCCAAGAT 3'

R: 5' CTTCTTCTTCCAGAAGGCC 3'

30 cycles, $94^{\circ} \mathrm{C}$ denaturation, $60.5^{\circ} \mathrm{C}$ annealing, and $72^{\circ} \mathrm{C}$ extension

The PCR product of allele detection CA was performed by Sanger Sequencing method. The PCR product of the VNTR polymorphism was separated on $8 \%$ polyacrylamide gel and alleles were detected. The restriction enzyme used for digestion in the RFL-PCR reaction was Fnu4HI. The digestion products of RFLP polymorphism were separated on $1 \%$ agarose gel. Types and sizes of different alleles for each polymorphism are described in Table 1.

Table 1. Several Alleles of CA and VNTR Polymorphisms of MAOAGene

\begin{tabular}{|lc|}
\hline Gene, Allele & Length, bp \\
\hline MAOA-CA & 128 \\
\hline a0 & 128 \\
\hline a1 & 124 \\
\hline a2 & 122 \\
\hline a3 & 120 \\
\hline a4 & 118 \\
\hline a5 & 116 \\
\hline a6 & 114 \\
\hline a7 & 112 \\
\hline a8 & 110 \\
\hline a9 & 108 \\
\hline a10 & \\
\hline MAOA-VNTR & $375-388$ \\
\hline V1 & $355-365$ \\
\hline V2 & $335-345$ \\
\hline V3 & $315-325$ \\
\hline V4 & $295-305$ \\
\hline V5 & \\
\hline RFLP & 180 \\
\hline R & 65 \\
\hline R & \\
\hline
\end{tabular}


We usedOpenEpisoftwarefor the statistical analysis of the data (http://www.openepi.com/menu/OPENEpi:Menuhtm). Chi-square and Fisher exact Test were used to compare frequency of the genotypes.

\section{Results}

\subsection{Genotyping and Association Analysis}

Three polymorphisms of MAOA gene, CA, VNTR and RFLP were genotyped in our case-control groups (Table 2). Regarding MAOA-CA polymorphism, 11 alleles for males and 10 alleles for females were found in patients group. In the control group, 10 alleles were found for each male and female participants. There was no female participant with a10 or 108bp allele in our study group. RegardingMAOAVNTR polymorphism, we identified 4 alleles in both males and females in patient samples, and in control group, 4 and 5 alleles for males and females, respectively. For this polymorphism, no V5 or 295-305 bp allele was identified. Regarding MAOA-RFLP, there are 2alleles for both males and females consisting of R1 an uncut allele and $\mathrm{R} 2$ the cut allele.
Allele frequencies of 3 analyzed polymorphisms were compared between patient and control groups and also between males and females of study population, using $\chi 2$ test and SPSS software.

According to the obtained information, for MAOA-CA polymorphism, no difference was observed in distribution of alleles between patient and control groups. But, comparing males and females, there was an association between the MAOA-CA polymorphism and bipolar disorder among females $(\chi 2=20.245, \mathrm{df}=9, \mathrm{P}=0.016)$ (Table 3 ). Regarding MAOA-VNTR polymorphism, a significant deviation from the normal allele distribution was observed between patients and controls for $\mathrm{V} 4$ allelic subgroup ( $\chi 2$ $=10.04, \mathrm{df}=1, \mathrm{P}=0.002$ ). However, association in this subgroup was just observed in females. On the whole, counting all VNTR allelic subgroups, another significant difference in allelic distribution was found in female patients compared to controls, but there was no such a result for males (Table 4).

Similarly, no deviation was observed comparing total patient and control groups. Regarding MAOA-RFLP, statistical analysis showed no significant association between the marker and bipolar disorder (Table 5).

\begin{tabular}{|c|c|c|c|c|c|c|}
\hline \multirow{2}{*}{ Allele } & \multicolumn{3}{|c|}{ Patients } & \multicolumn{3}{|c|}{ Controls } \\
\hline & Male & Female & Total & Male & Female & Total \\
\hline \multicolumn{7}{|l|}{ CA } \\
\hline Total & 50 & 106 & 156 & 53 & 120 & 173 \\
\hline \multicolumn{7}{|l|}{ VNTR } \\
\hline V1 & $2(4)$ & $17(16)$ & & $7(13.2)$ & $24(21.4)$ & \\
\hline V2 & $27(54)$ & $48(45.3)$ & & $30(56.6)$ & $51(45.5)$ & \\
\hline V3 & $6(12)$ & $7(6.6)$ & & $5(9.4)$ & $19(17)$ & \\
\hline V4 & $15(30)$ & $34(32.1)$ & & $11(20.8)$ & $16(14.3)$ & \\
\hline V5 & $0(0)$ & $0(0)$ & & $0(0)$ & $2(1.8)$ & \\
\hline Total & 50 & 106 & 156 & 53 & 120 & 173 \\
\hline \multicolumn{7}{|l|}{ RFLP } \\
\hline R1 & $27(54)$ & $71(71)$ & & $24(48)$ & $75(75)$ & \\
\hline $\mathrm{R} 2$ & $23(46)$ & $29(29)$ & & $26(52)$ & $25(25)$ & \\
\hline Total & 50 & 106 & 156 & 60 & 113 & 173 \\
\hline
\end{tabular}

$\mathrm{a}$ Data are presented as No. or No. (\%).

Table 3. Statistical Analysis of MAOA-CA in Males and Females

\begin{tabular}{lccc}
\hline & $\boldsymbol{\chi 2}^{\mathbf{2}}$ & df & PValue $^{\mathrm{a}}$ \\
\hline Gender & & & \\
\hline Male & 8.401 & 10 & $0.590^{\mathrm{a}}$ \\
Female & 20.245 & 9 & 0.016 \\
Total & 10.286 & 10 & 0.416 \\
\hline $\mathrm{a}_{\mathrm{P}<0.05}$ & & &
\end{tabular}

${ }^{\mathrm{a}} \mathrm{P}<0.05$. 
Eslami Amirabadi MR et al.

\begin{tabular}{lccc}
\hline \multicolumn{4}{l}{ Table 4. MAOA-VNTR V4Allele and Total Allelic Distribution } \\
\hline Allele & $\boldsymbol{\chi 2}$ & $\mathbf{d f}$ & PValue $^{\mathrm{a}}$ \\
\hline $\mathbf{V 4}$ & & & \\
Male & 1.165 & 1 & 0.280 \\
\hline Female & 9.651 & 1 & 0.002 \\
\hline Total & 10.046 & 1 & 0.002 \\
\hline Total & & & \\
\hline Male & 3.558 & 3 & 0.313 \\
\hline Female & 15.151 & 4 & 0.004 \\
\hline Total & 14.509 & 4 & 0.006 \\
\hline a $\mathrm{P}<0.05$. & & & \\
\hline
\end{tabular}

\begin{tabular}{lccc}
\hline \multicolumn{4}{l}{ Table 5. RFLP Allele and Total Allelic Distribution } \\
\hline RFLP & $\chi \mathbf{2}$ & df & P Value $^{\mathrm{a}}$ \\
\hline Gender & & & \\
Male & 0.360 & 1 & 0.548 \\
Female & 0.406 & 1 & 0.524 \\
Total & 0.015 & 1 & 0.903 \\
\hline a $\mathrm{p}<0.05$ & & &
\end{tabular}

all sample and another obvious association between V4 allele and the disorder, both just in females. Some studies $(10,14,15,31)$ have shown the association of this marker to bipolar disorder and specifically in females while other studies $(23,40)$ found no association. It is stated that the long alleles of this polymorphism are transcriptional and more active than the shorter alleles (41) that matches our findings.

Regarding MAOA-RFLP marker, we replicated the results of most previous studies; similar to our results, Parsian and Todd (19), and Craddock et al. (40) found no association between this marker and bipolar disorder. However, two studies $(29,31)$ have found an association for this marker in females and also in general comparison between overall sample and control group.

According to many studies mentioned above, those have reported significant gender-specific associations of MAOA gene with psychiatric disorders; it seems that MAOA based etiology of BPD may be different in males and females.

Our different results compared to other studies, show that the allele frequencies of such polymorphisms are population and ethnic specific, and some factors like genetic background and founder effects may affect the allele frequencies in different populations. The allele typing difficulties due to close allele sizes in polymorphic markers may be another affecting factor, as well. Thus, more studies using larger sample groups and also association analysis of these polymorphisms with BPD subtypes (with different symptoms) are suggested to achieve more reliable results. Overall, our results show that CA and VNTR polymorphisms are associated with bipolar disorder in Iranian population, and could be used as risk factors in the diagnosis of at risk people.

It was the first time in Iran that a study was conducted on the role of MAOA gene polymorphisms (CA microsatellite, VNTR and RFLP) in the etiology of bipolar disorder in Iranian population. A larger sample size is required to find more valid results. polymorphisms of MAOA gene in our study to be more precise.

In our sample group, we replicated some previous results of MAOA-CA, MAOA-VNTR and MAOA-RFLP association studies with the bipolar disorder. Our results were similar to that of Preisig et al. (30), regarding the difference between the allelic distributions of female patient and control groups. However, we found no difference in the overall sample, and no particular allele in association with the disease, as they showed an association of a6 allele with the disease in female group. Similarly, Lim et al. (31) reported the allelic distribution differences in overall sample and control groups and also association of a2 and a5 alleles with the disorder in females group. Unlike the mentioned studies, Craddock et al. (40) found no relationship between $M A O A-C A$ marker with bipolar disorder. Regarding MAOA-VNTR, there is discrepancy in reported results of different studies. We found a significant association between VNTR marker and bipolar disorder in over-

\section{Acknowledgements}

We would like to thank our patients and their families for their participation, also Mrs Simasadat Noorbakhsh for her cooperation in editing the manuscript.

\section{Funding/Support}

This study was funded by Behavioral Sciences Research Centre of Shahid Beheshti University of Medical Sciences.

\section{References}

1. Merikangas KR, Jin R, He JP, Kessler RC, Lee S, Sampson NA, et al. Prevalence and correlates of bipolar spectrum disorder in the world mental health survey initiative. Arch Gen Psychiatry. 2011;68(3):241-51.

2. Maier W, Hallmayer J, Minges J, Lichtermann D. Morbid risks in relatives of affective, schizoaffective, and schizophrenic patients-results of a family study, in Affective and Schizoaffective Disorders-Sim- 
ilarities and Differences. Marneros A, Tsuang T editors. New York: Springer; 1990.

3. Van Snellenberg JX, de Candia T. Meta-analytic evidence for familial coaggregation of schizophrenia and bipolar disorder. Arch Gen Psychiatry. 2009;66(7):748-55.

4. Lichtenstein P, Yip BH, Bjork C, Pawitan Y, Cannon TD, Sullivan $\mathrm{PF}$, et al. Common genetic determinants of schizophrenia and bipolar disorder in Swedish families: a population-based study. Lancet. 2009;373(9659):234-9.

5. Edvardsen J, Torgersen S, Roysamb E, Lygren S, Skre I, Onstad S, et al. Heritability of bipolar spectrum disorders. Unity or heterogeneity? J Affect Disord. 2008;106(3):229-40.

6. Peerbooms OL, van Os J, Drukker M, Kenis G, Hoogveld L, Mthfr in Psychiatry Group, et al. Meta-analysis of MTHFR gene variants in schizophrenia, bipolar disorder and unipolar depressive disorder: evidence for a common genetic vulnerability? Brain Behav Immun. 2011;25(8):1530-43.

7. Hsu YP, Powell JF, Sims KB, Breakefield XO. Molecular genetics of the monoamine oxidases. J Neurochem.1989;53(1):12-8.

8. Brunner HG, Nelen M, Breakefield XO, Ropers HH, van Oost BA. Abnormal behavior associated with a point mutation in the structural gene for monoamine oxidase A. Science. 1993;262(5133):578-80.

9. Craddock N, O'Donovan MC, Owen MJ. The genetics of schizophrenia and bipolar disorder: dissecting psychosis. J Med Genet. 2005;42(3):193-204.

10. Fan M, Liu B, Jiang T, Jiang X, Zhao H, Zhang J. Meta-analysis of the association between the monoamine oxidase-A gene and mood disorders. Psychiatr Genet. 2010;20(1):1-7.

11. Brummett BH, Krystal AD, Siegler IC, Kuhn C, Surwit RS, Zuchner S, et al. Associations of a regulatory polymorphism of monoamine oxidase-A gene promoter (MAOA-uVNTR) with symptoms of depression and sleep quality. Psychosom Med. 2007;69(5):396-401.

12. Yu YW, Tsai SJ, Hong CJ, Chen TJ, Chen MC, Yang CW. Association study of a monoamine oxidase a gene promoter polymorphism with major depressive disorder and antidepressant response. Neuropsychopharmacology. 2005;30(9):1719-23.

13. Lee SY, Hahn CY, Lee JF, Huang SY, Chen SL, Kuo PH, et al. MAOA interacts with the ALDH2 gene in anxiety-depression alcohol dependence. Alcohol Clin Exp Res. 2010;34(7):1212-8.

14. Hu MC, Lee SY, Wang TY, Chen SL, Chang YH, Chen SH, et al. Association study of DRD2 and MAOA genes with subtyped alcoholism comorbid with bipolar disorder in Han Chinese. Prog Neuropsychopharmacol Biol Psychiatry. 2013;40:144-8.

15. Contini V, Marques FZ, Garcia CE, Hutz MH, Bau CH. MAOA-uVNTR polymorphism in a Brazilian sample: further support for the association with impulsive behaviors and alcohol dependence. Am J Med Genet B Neuropsychiatr Genet. 2006;141B(3):305-8.

16. Chen Y, Zhang J, Zhang L, Shen Y, Xu Q. Effects of MAOA promoter methylation on susceptibility to paranoid schizophrenia. Hum Genet. 2012;131(7):1081-7.

17. Sun Y, Zhang J, Yuan Y, Yu X, Shen Y, Xu Q. Study of a possible role of the monoamine oxidase A (MAOA) gene in paranoid schizophrenia among a Chinese population. Am J Med Genet B Neuropsychiatr Genet. 2012;159B(1):104-11.

18. Nothen MM, Eggermann K, Albus M, Borrmann M, Rietschel M, Korner J, et al. Association analysis of the monoamine oxidase $\mathrm{A}$ gene in bipolar affective disorder by using family-based internal controls. Am J Hum Genet. 1995;57(4):975-8.

19. Parsian A, Todd RD. Genetic association between monoamine oxidase and manic-depressive illness: Comparison of relative risk and haplotype relative risk data. Am J Med Genet.1997;74(5):475-9.

20. Turecki G, Grof P, Cavazzoni P, Duffy A, Grof E, Ahrens B, et al. MAOA: association and linkage studies with lithium responsive bipolar disorder. Psychiatr Genet. 1999;9(1):13-6.

21. De Luca V, Tharmalingam S, Sicard T, Kennedy JL. Gene-gene interaction between MAOA and COMT in suicidal behavior. Neuro- sci Lett. 2005;383(1-2):151-4.

22. Lin S, Jiang S, Wu X, Qian Y, Wang D, Tang G, et al. Association analysis between mood disorder and monoamine oxidase gene. Am J Med Genet. 2000;96(1):12-4.

23. Huang SY, Lin MT, Shy MJ, Lin WW, Lin FY, Lu RB. Neither singlemarker nor haplotype analyses support an association between monoamine oxidase A gene and bipolar disorder. Eur Arch Psychiatry Clin Neurosci. 2008;258(6):350-6.

24. Kawada Y, Hattori M, Dai XY, Nanko S. Possible association between monoamine oxidase A gene and bipolar affective disorder. Am J Hum Genet. 1995;56(1):335-6.

25. Muller DJ, Serretti A, Sicard T, Tharmalingam S, King N, Artioli $\mathrm{P}$, et al. Further evidence of MAO-A gene variants associated with bipolar disorder. Am J Med Genet B Neuropsychiatr Genet. 2007;144B(1):37-40.

26. Wang DX, Jiang KD, Qian YP. A study of association between MAO gene and the bipolar affective disorder with psychiatric symptoms [J]. Medical Journal of Chinese People Heacth. 2005;9:000. Med J Chinese People Health. 2005.

27. Lin YM, Davamani F, Yang WC, Lai TJ, Sun HS. Association analysis of monoamine oxidase A gene and bipolar affective disorder in Han Chinese. Behav Brain Funct. 2008;4:21.

28. Savitz J, van der Merwe L, Solms M, Ramesar R. A linkage and family-based association analysis of a potential neurocognitive endophenotype of bipolar disorder. Neuromolecular Med. 2007;9(2):101-16.

29. Rubinsztein DC, Leggo J, Goodburn S, Walsh C, Jain S, Paykel ES, Genetic association between monoamine oxidase A microsatellite and RFLP alleles and bipolar affective disorder: analysis and meta-analysis. Hum Mol Genet. 1996;5(6):779-82.

30. Preisig M, Bellivier F, Fenton BT, Baud P, Berney A, Courtet P, et al Association between bipolar disorder and monoamine oxidase A gene polymorphisms: results of a multicenter study. Am J Psychiatry. 2000;157(6):948-55.

31. Lim LC, Powell J, Sham P, Castle D, Hunt N, Murray R, et al. Evidence for a genetic association between alleles of monoamine oxidase A gene and bipolar affective disorder. Am J Med Genet. 1995;60(4):325-31.

32. Black GC, Chen ZY, Craig IW, Powell JF. Dinucleotide repeat polymorphism at the MAOA locus. Nucleic Acids Res.1991;19(3):689.

33. Hinds HL, Hendriks RW, Craig IW, Chen ZY. Characterization of a highly polymorphic region near the first exon of the human MAOA gene containing a GT dinucleotide and a novel VNTR motif. Genomics. 1992;13(3):896-7.

34. Hotamisligil GS, Breakefield XO. Human monoamine oxidase A gene determines levels of enzyme activity. Am J Hum Genet. 1991;49(2):383-92.

35. Nezu A, Nezu C. Evidence-based outcome research. A practica guide to conducting randomized controlled trials for psychosocia interventions.New York: Oxford University Press; 2008.

36. First MB, Spitzer RL, Gibbon M, Williams JB. Structured Clinical Interview for DSM-IV® Axis I Disorders (SCID-I), Clinician Version, Administration Booklet.Arlington: American Psychiatric Pub; 2012.

37. Baron M. Manic-depression genes and the new millennium: poised for discovery. Mol Psychiatry. 2002;7(4):342-58.

38. Fortinash KM, Holoday-Worret PA. Psychiatric mental health nursing.: Mosby; 2008.

39. McDermott R, Tingley D, Cowden J, Frazzetto G, Johnson DD. Monoamine oxidase A gene (MAOA) predicts behavioral aggression following provocation. Proc Natl Acad Sci U S A. 2009;106(7):2118-23.

40. Craddock N, Daniels J, Roberts E, Rees M, McGuffin P, Owen M] No evidence for allelic association between bipolar disorder and monoamine oxidase A gene polymorphisms. Am J Med Genet. 1995;60(4):322-4.

41. Sabol SZ, Hu S, Hamer D.A functional polymorphism in the monoamine oxidase A gene promoter. Hum Genet.1998;103(3):273-9. 